\title{
Practice and Reflection to the Quality Improving of Adult Higher Education
}

\author{
KANG Chun-yan ${ }^{1, a}$ \\ ${ }^{1}$ Tianjin Radio and TV University, Teaching resources management and construction office, T \\ ianjin 300191, China \\ atjkangcy@163.com
}

Keywords: Adult Higher Education, teaching quality, practical measures

\begin{abstract}
Great efforts have been made to cultivate higher education, and the Adult Higher Education, an important part of the field, makes its own steady progress. But there are restrictions existed. Based on the current teaching situation, this essay offers proposals such as establishing sophisticated teaching management system, achieving standardized management, and cultivating excellent teachers to improve the teaching quality.
\end{abstract}

There are also detailed practical measures to accelerate the pace of the Adult Higher Education: curriculum reforming, teaching content optimizing, examination system and public trust perfecting and improving.

\section{Introduction}

At present, Adult Higher Education carries a big weight in China's higher education, and has formed its own scale and social impact. With the rapid development of society, more and more people urge for lifelong learning, which protrudes the importance of Adult Higher Education. However, its problems do exist along with the outstanding contribution to the country.

Disadvantages like non-standardized management, low quality of teachers, outdated teaching content and unauthorized assessments are in the way of its development and quality improving. A series of practical measures are needed to solve these problems to ensure the quality of Adult Higher Education and realize its sustainable development.

\section{Elements restrain Adult Higher Education quality improving}

\section{A. Non-standardized teaching management}

China's Adult Higher Education has a short history and weak foundation. Up to now, complete rules and a perfect administrative regulation system has not been founded. Imitating the teaching patterns of General Higher Education, China's Adult Higher Education has no practical and distinctive teaching theories and contents.

Besides, blindly pursuing to school scale and economic benefits, the sponsoring organizations often neglect the fundamental task and real purpose of AdultHigher Education. Highly qualified teachers are hard to employ with the downgraded education input to maximize the economic benefit.

As most students of Adult Higher Education are serving officers, having their own pressure from work and family, and with the low attendance rate caused by unavoidable reasons, they often have little learning initiative and failed tofulfill the assignments on time, which decreases the learning efficiency. The only purpose of their attendance is for the graduation certification, not for practice. 


\section{B. Low-qualified faculty}

The target of Adult Higher Education has its own specialty, differ a lot in psychological and knowledge structure from general students, which determines the difference in teaching management and content with General Higher Education.

Having no professional trainers, Adult Higher Education in many colleges have to borrow teachers from other colleges and schools, having no professional managing and teaching training. Much more students get in with the recent years' enrollment expansion, causing the serious shortage of teachers. A disordered student-staff ratio.

The energy-limited instructors, having students both in the General and Adult Higher Education, obviously put more into the former, their original profession. Failing to master the teaching content and method of Adult Higher Education completely, the instructors mostly copy their teachings for the General, which failed to achieve the expected effects and decreases the teaching quality.

\section{Outdated teaching content}

Textbook, the main carrier of Adult Higher Education, should be adult oriented to reflect the specialty, and plays a crucial role in professional learning. However, textbooks completely suit for Adult Higher Education are few.

According to the surveys, most teachers mechanically apply the textbooks ofGeneral Higher Education, which are already out of date. Students of Adult Higher Education are mostly serving officers, needing different teaching degreesfrom general students. Teaching pattern and content of General Higher Educationshould not be applied in practical teaching, which goes ill with their level of expertise.

\section{Unauthorized assessments}

Presently, most students attend the Adult Higher Education for career advance and professional title appraisal rather than practical application. In addition, curriculum and examination proposition of current Adult Higher Education have no standards, varies from different colleges according to their own actual situation.

The contents of examination featured on the theoretical knowledge, lacking the practical and having no characteristic of adult education. Moreover, the single method close examination is filled with multi-choices, blank fillings and short answer questions, paying little attention to the innovative thinking and professional knowledge application. And the results are impractical.

Furthermore, as students of the Adult Higher Education mostly have work and family, only limited time is available for study, their low attendance rate and weak foundation make it difficult for a vigorous test. Schools, to ensure the graduation rate, often require the student reciting rather than thinking, having no guiding significance to their work. And the check results are short of credibility since cheating is very common.

\section{Concrete practical measures to improve the teaching quality of Adult Higher Education}

\section{A. Establishing sophisticated teaching management system, achieving standardized management}

With the rapid development of China's economy, the market and all industries are pressing for more professionals. To survive in this vigorous world widecompetition, it is the Adult Higher Education that should cultivate all-round talents for China's economic construction. Therefore, a sophisticated management system is needed, along with a corrected guiding thought, intensified quality sense, strengthened and standardized teaching administration; efforts should be put into practice.

First, make the unit in charge clear. The unit that manage the Adult Higher Education should take the responsibility, and the situation of multiple management in name but unattended 
management in reality should be avoided to ensure the smooth and highly active transmission of information.

We should also gradually perfect the laws and regulations of Adult Higher Education along with the institution construction to definite the main bodies' responsibilities, obligations and rights and regulate the school-running actions.

Moreover, the education authorities can have their own planning according to their own characteristics. Like employing highly qualified, experienced retired teachers as supervisors to supervise the teaching conditions, processes, class management and students' learning progresses. The supervisors should also summarize the questions in the class, make their opinions and then give an account of the result to the charging unit, therefore forming a benign evaluation information feedback system.

Second, reform the examination system. The main difference between the Adult Higher Education and the General is that in examinations the former think highly of knowledge application while take no account of theoretical research.

The point of Adult Higher Education is to cultivate the students' practical abilities rather than theoretical knowledge. So, innovation and practical abilities should be emphasized in exams. Open book examinations should be carried out.Students have their own heads to apply the theoretical knowledge into practical.Great improvement can be made in independent thinking, practical application and innovation abilities.

Third, introduce the credit system. This flexible teaching management system set a certain amount of credits which can be earned by studying any subject. Students can graduate when they got all the credits. The system has no rigid requirements for the period of schooling. It suits the actual characteristic of Adult Higher Education solving the students' real problems in a relatively humanized way by letting students arrange their own curriculum freely.

The learning hours of employed students are incompatible with working and family time. With the credit system, the students can arrange their time more reasonably, learn in accordance with their own aptitude and arouse their interests.

\section{B.Cultivating excellent teachers to improve teaching quality}

The teachers' professional quality and teaching levels decide the quality of Adult Higher Education. The educational institution should strengthen the economic input to the faculty and employ full-time teachers of professional, experienced, responsible and qualified. Brilliant graduates from colleges and universities can also be invited to build a team of excellent teachers. Regular training and arousing enthusiasm of teaching is needed.

Incentive programs are inevitable to select the superior of student-centred and eliminate the inferior of low professional quality. The Adult Higher Education calls for more brilliant teachers to improve its quality and to help students’ practical application.

\section{C.Reforming the curriculum and optimizing teaching content}

For the students, their main learning target is to master the theological knowledge and apply it into social practice. Class time is the only way that they can learn knowledge, which can be skillfully applied to practice only when thoroughly understood. The primary problem the Adult Higher Education institution should first explore is how to set the curriculum, perfect the teaching content and clear the goal and direction at the premise of suiting all different vocational skills.

First of all, the specialized features of Adult Higher Education should be emphasized in the curriculum, the enriched learning content strengthened the direct and indirect links between courses, course and students, theological and practical lessons.

Then to perfect the teaching content with adjustments of revising, deleting, combining and adding. Deleting the out-dated, irrelevant content, combing two or more courses of sameness, adding operable and effective ones that are easy to spread and to the point, and holding the content that can help students improve their all-round abilities and get employed or self-employed. 
Textbooks also count as it directly affects the quality of teaching and learning. A good textbook is very serious but easy to understand. Assorted reference materials and exercise books are necessary to help students to better master and consolidate the knowledge learned in class, thus apply the theoretical into practical.

Teacher, taking students as friends and as teaching objects, should know their thoughts, strengthen the communication and arouse their initiative and enthusiasm. To teach students in accordance with their aptitude, teachers cultivate their self-learning, problem analyzing and solving abilities.

\section{D.Perfecting examination system and improving its public trust}

One of the ways to check the students' proficiency in relative knowledge and learning conditions is examination. A vigorous examination system can remediate the exam atmosphere, strengthen the construction of style of study, and accelerate the development of Adult Higher Education in a healthy, orderly, judicial and equitable background. The varied course assessments can have different tailored criteria to different students in accordance with their own characteristics due to their varied education degrees and backgrounds.

Implement of a comprehensive scoring system includes the attendance, basic knowledge mastery, class activity, independent thinking and innovative ideas. They do not need exams that only ask them to recite the content on books. It is the actual practical application ability that counts. A serious examination atmosphere should be strengthened by arranging responsible new teachers as supervisors, making strict disciplines and forbidding cheating to improve the public trust to the examination.

In short, Adult Higher Education is walking into orbit by gradually developing. It is our responsibility to break the barriers one by one and push the career into a new chapter.

\section{References}

[1] E. Crawley. Rethinking Engineering Education, 2007

[2] Wooden,Sharon and others. ORIDING: An Adult Teaching-Learning Technique. Adult L earning, 1994.

[3] N.C. Burbules. Dialogue in Teaching, 1993

[4] Legge,D. The Education of Adults in Britain, 1982

[5] National Advisory Council on Adult Education. Terms, Definitions, Organizations and C ouncils Associated with Adult Learning, 1980

[6] Jarvis. An International Dictionary of Adult and Continuing Education,1990 